\title{
Optimization of Ceramic Paste Viscosity Use for the Elaboration of Tubular Membrane Support by Extrusion and Its Application
}

\author{
Celestine Asobo Yanu, Joseph Marie Sieliechi, Martin Benoit Ngassoum \\ National School of Agro-Industrial Sciences, Department of Applied Chemistry, University of Ngaoundéré, Ngaoundéré, \\ Cameroon \\ Email: yanucelest@yahoo.com, jsieliechi@yahoo.fr, ngassoum@yahoo.fr
}

How to cite this paper: Yanu, C.A., Sieliechi, J.M. and Ngassoum, M.B. (2020) Optimization of Ceramic Paste Viscosity Use for the Elaboration of Tubular Membrane Support by Extrusion and Its Application. Journal of Materials Science and Chemical Engineering, 8, 1-22.

https://doi.org/10.4236/msce.2020.83001

Received: January 13, 2020

Accepted: March 2, 2020

Published: March 5, 2020

Copyright $\odot 2020$ by author(s) and Scientific Research Publishing Inc. This work is licensed under the Creative Commons Attribution International License (CC BY 4.0).

http://creativecommons.org/licenses/by/4.0/

\begin{abstract}
The objective of this work was to determine the optimum size and amount of raw materials which influence the viscosity of ceramic paste using the experimental design for the production of tubular support by the extrusion technique and its application in microfiltration. The Box Behnken design was used to optimize the viscosity of the ceramic paste. ANOVA was used to model the system represented by independent parameters and dependent output response and to optimize the system by estimating the statistical parameters. A three-factor and three-level design was used generating thus 15 experiments. The independent factors were the amount of porogen, size of porogen and amount of binder and dependent factor the viscosity of the ceramic paste. The minimum $(-1)$, intermediate $(0)$ and maximum $(+1)$ level of the amount of porogen, size of porogen and amount of binder used were $20 \mathrm{~g}$, $30 \mathrm{~g}$ and $40 \mathrm{~g}, 50 \mu \mathrm{m}, 100 \mu \mathrm{m}$ and $150 \mu \mathrm{m}$, and $2 \mathrm{~g}, 3.5 \mathrm{~g}$ and $5 \mathrm{~g}$ respectively. The statistical analyses showed that the values of the answers would adapt to a second degree polynomial model. The R-square value obtained was greater than 95\%, the Biais factor was equal to the unit and the Absolute Average Deviation (AAD) equal to the zero thus validating the model. The optimal size of raw material was found to be $100 \mu \mathrm{m}$ for an amount of clay of $66 \mathrm{~g}$, amount of porogen of $30 \mathrm{~g}$ and amount of binder of $4 \mathrm{~g}$. The optimum viscosity of the ceramic paste was found to be $26.7 \mathrm{~Pa} \cdot \mathrm{s}$ which is close to the viscosity of the clay paste only found to be $28.5 \mathrm{~Pa} \cdot \mathrm{s}$, thus good for shaping by the extrusion technique. The ceramic paste showed a pseudo-plastic behavior. The tubular porous support was sintered at $950^{\circ} \mathrm{C}$ and the dimensions, such as outer and inner diameters and length of the tube were $4 \mathrm{~cm}, 2 \mathrm{~cm}$, and 19 $\mathrm{cm}$, respectively. The sintered membrane possesses a porosity of $43.5 \%$, water permeability of $244.9 \mathrm{~L} / \mathrm{h} \cdot \mathrm{m}^{2}$ bar, an average pore size of $2.4 \mu \mathrm{m}$ and mechan-
\end{abstract}


ical strength of 9.2 MPa with very good corrosion resistance in acidic and basic conditions. The membrane was subjected to microfiltration of synthetic clay suspension at various combinations of applied pressures $(0.5-2$ bar $)$ with a feed concentration of 100 NTU. An increase in the applied pressure leads to an increase in the flow rate and retention rate. The flow rate decreases steadily with time. The highest retention was obtained at 2 bar with permeability of $184.69 \mathrm{~L} / \mathrm{h} \cdot \mathrm{m}^{2}$ bar and a retention of $96 \%$ decreasing the turbidity to about $3.5 \mathrm{NTU}$ which is below the acceptable value of $5 \mathrm{NTU}$.

\section{Keywords}

Optimization, Tubular Support, Extrusion, Viscosity of Paste, Microfiltration

\section{Introduction}

In Cameroon, particularly in Ngaoundere about $30 \%-48 \%$ of the rural population do not have access to tap water [1]. They generally use well water, river water and other sources for drinking but the lather contains high turbidity values. Water supplied in the urban area in the other hand also contains suspended particles [2]. These suspended particles are vectors of water borne diseases such as typhoid, cholera, diarrhea etc. The turbidity of these waters is higher than the acceptance standard value of $5 \mathrm{NTU}$ [3]. The water treatment techniques used to ameliorate the quality of the water include coagulation/flocculation/decantation but this uses chemicals, tissue filtration eliminates only suspended particles, adsorption eliminates only dissolved substances and membrane filtration which has the advantage of eliminating both suspended and dissolved substances [4]. These membranes are inorganic membrane made from metal oxides $\left(\mathrm{Al}_{2} \mathrm{O}_{3}\right.$, $\mathrm{ZrO}_{2}, \mathrm{TiO}_{2}$ ) and more recently from clay and have the advantage that they can be applied in extremely aggressive environments due to their distinct advantages, including good thermal stability, mechanical strength, chemical resistance, long life span and defouling properties [5] [6]. Membranes made from clay have the advantage of being available and inexpensive in Cameroon than those made from metal oxides. We have different forms of clay membrane filters such as disc, cylindrical and tubular support. The latter has the advantage of offering less fouling during filtration. The raw materials used are clay (which is the mineral material), porogen (responsible for the formation of pores) and binder (for rheological properties). Choosing the appropriate size and proportion of raw material plays an important role in the viscosity of the ceramic paste for shaping by extrusion. Parameters influencing the viscosity of the ceramic paste are the size and proportions of raw materials. Shaping by extrusion is achievable only if the ceramic paste created from starting materials has rheological characteristics similar to those of clays paste only [7]. The challenging task for the upcoming elaboration of tubular porous support is obtaining the optimal size and proportion of raw material that gives rise to an optimal viscosity allowing shaping of 
the ceramic paste by extrusion. As a consequence, currently, many researches targeted on the development of ceramic membranes with utilization of less expensive materials such as apatite powder, dolomite, pyrophylite, Moroccan clay and kaolin, etc. [8] [9]. Talidi et al. [8] prepared the tubular macroporous membrane using Pyrophylite clay via extrusion and followed by a sintering process. The properties of the porous pyrophyllite membrane were discussed as a function of sintering temperature in order to optimize the preparation conditions. Saffaj et al. [10] prepared membrane support using Moroccan clay as a raw material by extrusion of the clay paste. The structural and mechanical properties of fabricated low cost membrane support were found suitable for membrane applications. Masmoudi et al. [11] produced tubular porous support using natural apatite powder and suggested for ultrafiltration (UF) and microfiltration (MF) applications. Bouzerara et al. [9] constructed membrane support from mixtures of doloma and kaolin. They strongly recommended that prepared support can be utilized for MF and UF processes. In this research works, the researchers used one variable at a time for the mixing of the raw material in order to have a paste with viscosity similar to that of the clay. An experimental design can thus be used to determine the optimal values of raw materials needed.

Considering such research trends, the study presented here focuses on the determination of the optimal size and proportion of raw materials which influences the viscosity of ceramic paste by the Box-Behnken design for the production of tubular support by extrusion method and the evaluation of the separation performance in treatment of suspended water solutions.

\section{Materials and Methods}

Clay mineral was collected at a depth of about $1.5 \mathrm{~m}$ from a mining site located in Wack village, in the Adamawa region, at $50 \mathrm{~km}$ SW of Ngaoundere, Cameroon at an altitude of $708 \mathrm{~m}$, latitude $07^{\circ} 40.685 \mathrm{~N}$ and longitude $013^{\circ} 33.026 \mathrm{E}$. One of the organic additives needed in the paste formulation was red sawdust "Tectona grandis" obtained from a local wood milling factory in the teck locality in the Adamawa region (Ngaoundere). After collecting the raw clay and red sawdust, lumps, stones and other heavy particles were removed from the samples by sieving. Prior to use, the clay and sawdust were crushed and sieved through a $100 \mu \mathrm{m}$ sieve to obtain the finest fraction of particles. The other organic additive used was Polyvinyl Alcohol (PVA), used as a binder supplied by Applied Chemistry Department of the University of Ngaoundere.

\subsection{Characterization of Raw Material}

The chemical composition of the natural raw clay was analyzed using a wavelength dispersive X-ray fluorescence apparatus (Shimadzu, XRF-1800) to evaluate the proportions of impurities in the raw material as well as the Loss of Ignition (LOI). Elemental composition of the red sawdust sample was analyzed with energy dispersive analysis of X-ray spectroscopy (EDS) coupled to the Scanning Electron Microscope. Thermogravimetric analysis (TGA) and diffe- 
rential scanning calorimetry (DSC) analyses for both samples were performed using a $2960 \mathrm{TA}$ Instrument under argon from room temperature up to $1200^{\circ} \mathrm{C}$ at a heating rate of $5^{\circ} \mathrm{C} / \mathrm{min}$. The analysis was performed on the raw material to evaluate the thermal stability and the minimum sintering temperature required for membrane fabrication.

\subsection{Production and Optimization of Ceramic Paste Viscosity}

It has been reported in the literature that numerous factors can influence the viscosity of ceramic paste [12] [13]. These factors are the size and proportion of the raw materials (clay, porogen and binder). In order to determine the optimum size and proportion of raw materials which influence the viscosity of ceramic paste for the production of tubular support by extrusion technique, the Response Surface Methodology (RSM) was used. It is a statistical method that uses experimental data obtained from specified experimental design to model and optimize any process in which response of interest is influenced by several variables [14]. Primarily, this optimization is done by following three major steps viz., performing the statistically designed experiments, estimating the coefficients in a mathematical model and predicting the responses and examining the adequacy of the model [15]. RSM helps to enumerate the relationships between output variables called responses $(Y)$ and input variables called factors $\left(X_{i}\right)[16]$.

$$
Y=f\left(X_{1}, X_{2}, X_{3}, \cdots, X_{n}\right)
$$

A standard RSM design called Box-Behnken design was applied in the present work. This method is suitable for fitting a quadratic surface and it helps to optimize the effective parameters with a minimum number of experiments, as well as to analyze the interaction between the parameters [17]. Generally, the BoxBehnken for 3 factors implies three blocks, in each one, a factorial design $2^{2}$ which is represented by each pair of treatment while the third factor remains fixed at 0 . Thus the Box-Behnken design for 3 factors has 15 experiments (12 edges and 3 center points). The centre points are utilized to evaluate the experimental error and the reproducibility of the data.

The experimental sequence was randomized in order to minimize the effects of uncontrolled factors [18]. The outcome of each experimental run was analyzed and the response was correlated with three input factors for the viscosity of the ceramic paste through an empirical second degree polynomial equation as given by the following equation:

$$
Y_{i}=\beta_{0}+\sum \beta_{i} x_{i}+\sum \beta_{i i} x_{i}^{2}+\sum \beta_{i j} x_{i} x_{j}+\varepsilon
$$

where, $Y_{i}$ is the predicted response (viscosity of ceramic paste), $\beta_{0}$ the constant coefficient, $\beta_{i}$ the linear coefficients, $\beta_{i j}$ the interaction coefficients and $\beta_{i i}$ the quadratic coefficient [19]. ANOVA was used to model the system represented by independent parameters and dependent output response and to optimize the system by estimating the statistical parameters. The minimum $(-1)$, interme- 
diate (0) and maximum (+1) level of the amount of porogen, size of porogen and amount of binder were $20 \mathrm{~g}, 30 \mathrm{~g}$ and $40 \mathrm{~g}, 50 \mathrm{~g}, 100 \mu \mathrm{m}$ and $150 \mu \mathrm{m}$, and $2 \mathrm{~g}, 3.5$ $\mathrm{g}$ and $5 \mathrm{~g}$ respectively. The statistical experimental design as specified by the software is shown in Table 1.

Table 1. Experimental domain for the raw materials.

\begin{tabular}{cccccc}
\hline \multirow{2}{*}{ Factors } & Units & Variables & \multicolumn{3}{c}{ Levels/Variations } \\
\cline { 4 - 6 } & & & Lower (-1) & Centre (0) & Higher $(+1)$ \\
\hline Amount of porogen & $\mathrm{g}$ & $X_{1}$ & 20 & 30 & 40 \\
Size of porogen & $\mu \mathrm{m}$ & $X_{2}$ & 50 & 100 & 150 \\
Amount of binder (PVA) & $\mathrm{g}$ & $X_{3}$ & 2 & 3.5 & 5 \\
\hline
\end{tabular}

\section{Validation of the Models}

In order to put in the form of an equation the phenomenon observed and to make it possible to predict the answers in the field defined for the study, it is important to validate the empirical models obtained. To do that, the execution of the model was measured by comparing the values of the answers envisaged and those observed.

\section{- $\mathbf{R}^{2}$ determination Coefficient}

The analysis of the variance makes it possible to calculate very useful statistics: $\mathrm{R}^{2}$ or $\mathrm{R}$ square. These statistics are the ratio of the sum of squares of the calculated answers (corrected average) to the sum of squares of the measured answers (corrected average):

$$
\mathrm{R}^{2}=\frac{\text { corrected average sum of squares of the calculated answers }}{\text { corrected average sum of squares of the measured answers }}
$$

In addition to the linear regression coefficient $\left(R^{2}\right)$, other mathematical procedures and tools were used. Thus, Absolute Average Deviation (AAD) which informs about the average manipulation error, the Biais factor (Bf) were given according to following expressions:

- Absolute Average Deviation (AAD)

$$
\mathrm{AAD}=\frac{\sum_{i=1}^{p}\left(\frac{\left|Y_{\text {iexp }}-Y_{\text {ical }}\right|}{Y_{\text {iexp }}}\right)}{p}
$$

With: $Y_{\text {iexp }}$ the experimental answer and $Y_{\text {ical }}$ the calculated response starting from the model for an experiment $I ; p$ being the total number of experiments.

- Biais factor $(\mathrm{Bf})$

$$
\mathrm{Bf}=10^{B}
$$

The Biais $B$ is given by the relation:

$$
B=\frac{1}{n} \sum \log \left(\frac{Y_{\text {theo }}}{Y_{\text {obs }}}\right)
$$


Each experiment was carried out in triplicate. MINITAB version 2017 and Statgraphics plus software were used to analyze the obtained data.

The preparation of the ceramic paste was achieved by dry mixing the clay, red sawdust and binder powders in order to homogenize them and then wet mixed by adding $80 \mathrm{ml}$ of water. The paste is then aged by putting it in a plastic bag and placing it in the fridge for $24 \mathrm{~h}$ to ameliorate its plasticity to obtain the ceramic paste as shown in Figure 1 below. Table 4 shows the different sizes and proportions of raw material mixed to obtain a homogeneous paste. The viscosity of the paste was then measured using a viscosimetre marketed by the LAMY at $25^{\circ} \mathrm{C}$. A graph of viscosity against shear rate was then plotted in order to determine the flow behavior of the ceramic paste.

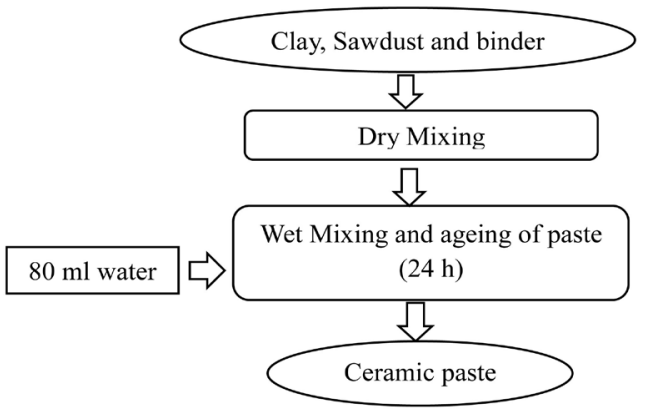

Figure 1. Production process of ceramic paste.

\subsection{Elaboration and Characterization of Tubular Membrane Support}

The ceramic paste produced from the optimal amount and size of raw material was fed into the extrusion cylinder. Then, evacuation piston forced the paste through a die in a tabletop extruder to form a tubular shape membrane. The tubular membrane was extruded in the horizontal at room temperature. When the tube reached the length of around $19 \mathrm{~cm}$, the process extruder stopped and the tube was removed. Then, the obtained tubular membrane was subjected to natural drying at room temperature for $24 \mathrm{~h}$. After this, the membrane was dried at $100^{\circ} \mathrm{C}$ for $24 \mathrm{~h}$ in a hot air oven. Subsequently, the membrane was taken to the sintering process with a heating rate of $2.5^{\circ} \mathrm{C} / \mathrm{min}$ until $500^{\circ} \mathrm{C}$ for $2 \mathrm{~h}$ and then $5^{\circ} \mathrm{C} /$ min until $950^{\circ} \mathrm{C}$ and sintered at that temperature for $2 \mathrm{~h}$ to obtain the tubular support as shown in Figure 2 below. These restrained thermal treatment steps were followed to avoid the formation of micro cracks and bends in the membrane. Finally, the elaborated membrane was washed with water and dried at $100^{\circ} \mathrm{C}$ for further characterization.

The porosity of the membrane was measured by utilizing water as a soaking agent (Archimedes method) [4]. The porosity of the membrane is measured using the below expression.

$$
\operatorname{Porosity}(\%)=\frac{W_{1}-W_{0}}{W_{1}} \times 100
$$




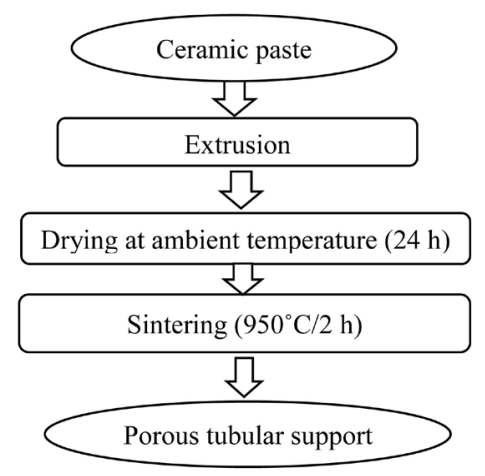

Figure 2. Production process of porous tubular ceramic support.

whereby the Dry filter is weighed $\left(W_{0}\right)$ and put into water for about $4 \mathrm{~h}$ in order to free the pores allowing the distilled water to be in the pores and then reweighed $\left(W_{1}\right)$ and the porosity is given by the difference between the mass of the filter before and after immersion in water divided by $W_{1}$.

The mechanical strength was determined by the compression test at three-point [5]. The corrosion resistance of the membrane was evaluated by means of loss of mass after treating in aggressive environments. The acid and alkali solutions were prepared as such $\mathrm{HNO}_{3}$ solution with $\mathrm{pH} 3$ and $\mathrm{NaOH}$ solution with $\mathrm{pH} 9$ and the membrane was soaked into the solutions for 6 days. The corrosion resistance of the recovered membrane was evaluated by weight decrement of the membrane [20].

The water permeability $\left(L_{h}\right)$ of the membrane was determined by the water flux at different applied pressures. It was evaluated from the slope of the pure water flux $\left(J_{W}\right)$ versus applied pressure across the membrane $(\Delta P)$ using the equation

$$
J_{W}=L_{h} \Delta P
$$

Hagen-Poiseuille equation was employed to estimate the average pore size of the membrane by assuming pores are cylindrical in shape [21] [22].

$$
J_{w}=\frac{\varepsilon r 2 \Delta P}{8 \mu \tau l}
$$

where, $\varepsilon$ is the porosity of the membranes, $r$ is the pore radius of the membrane (m), $\Delta P$ is the applied pressures across the membrane, $l$ is the pore length which is generally taken as thickness of the membrane, $\tau$ is the tortuosity factor (generally used as 1$)$, and $\mu$ is the viscosity of water $(0.00089 \mathrm{~Pa} \cdot \mathrm{s})$. By combining Equations (9) and (10), the corresponding pore radius of the membrane can be evaluated from:

$$
r=\sqrt{\frac{L h 8 \mu \tau l}{\varepsilon}}
$$

\subsection{Microfiltration System}

The laboratory scale diagram of the overall tangential microfiltration system is 
presented in Figure 3. The elaborated tubular ceramic membrane was incorporated into the module for tangential cross flow microfiltration. The feed solution was pumped to the module from the feed tank and the operating pressure was adjusted by hand operation using the flow control valves (security van). The permeate was collected in the permeate tank while the concentrated collected in the concentrated tank. The flow of the solution is shown by the arrows in Figure 3 below.

The water flux of the permeate was measured at different applied pressures ( $0.5-2$ bar) as a function of time by utilizing the equation below:

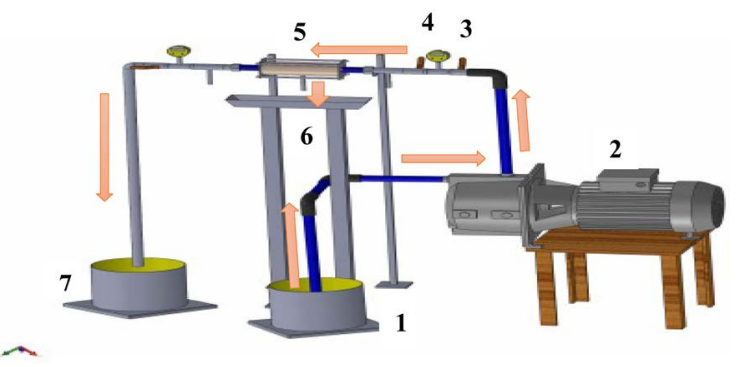

Figure 3. Laboratory Pilot scale of the experimental setup used for the microfiltration experiments: 1-Feed tank, 2-Electric pump, 3-Security Van, 4-manometer, 5-Tubular support Memebrane, 6-permeate tank and 7-Concentrate tank.

$$
J_{w}=\frac{Q}{A t}
$$

where, $Q$ is the permeated water in volume $\left(\mathrm{m}^{3}\right) ; A$ is the effective membrane area $\left(\mathrm{m}^{2}\right)$ and $t$ is the measured time (s).

A clay suspension of $2 \mu \mathrm{m}$ was prepared by soaking approximately $1 \mathrm{~kg} g$ of kaolinite clay sample in $3 \mathrm{~L}$ of distilled water for 24 hours. And let to rest for 8 hours to settle larger particles before decanting the liquid. The particle size distribution of the suspension is determined using master sizer 2000 and then brought to a turbidity of 100 NTU by dilution with distilled water using a Nephelometric Turbidimeter (HACH RATIO 2100A).

The tangential microfiltration study on the $2 \mu \mathrm{m}$ synthetic water suspension of turbidity $100 \mathrm{NTU}$ was performed at various applied pressures of $0.5-2 \mathrm{bar}$ and the observed retention was determined by below expression:

$$
R(\%)=\frac{C_{f}-C_{p}}{C_{f}} \times 100
$$

where $C_{f}$ is the suspension concentration in the feed stream, $C_{p}$ is the suspension concentration in the permeate stream and $R$ is the observed retention (\%).

\section{Result and Discussion}

\subsection{Characterization of Raw Materials}

\subsubsection{Chemical Characterization}

Chemical composition of the Wack clay determined by XRF is shown in Table

2. The Wack clay is predominantly composed of silica and alumina with a small 
amount of $\mathrm{Fe}_{2} \mathrm{O}_{3}, \mathrm{CaO}, \mathrm{K}_{2} \mathrm{O}, \mathrm{MgO}$ and $\mathrm{Na}_{2} \mathrm{O}$. The percentage of $\mathrm{Al}_{2} \mathrm{O}_{3}$ corresponds to non-refractory clay since it does not exceed $45 \%$ [23]. The presence of a high level $\mathrm{K}_{2} \mathrm{O}$ confirms that it can be used as a melting material in our formulation [24]. The Loss of ignition (L.O.I) of clay is in the range of $8 \%-18 \%$ allowable for ceramics [25]. The described composition of the powder corresponds to kaolinite clay according to the formula used by Kamseu [26].

Table 2. Chemical Composition of the wack clay by XRF (values are given at \pm 1 wt $\%$ ).

\begin{tabular}{lccccccccc}
\hline & $\begin{array}{c}\mathrm{SiO}_{2} \\
(\%)\end{array}$ & $\begin{array}{c}\mathrm{Al}_{2} \mathrm{O}_{3} \\
(\%)\end{array}$ & $\begin{array}{c}\mathrm{Fe}_{2} \mathrm{O}_{3} \\
(\%)\end{array}$ & $\begin{array}{c}\mathrm{CaO} \\
(\%)\end{array}$ & $\begin{array}{c}\mathrm{MgO} \\
(\%)\end{array}$ & $\begin{array}{c}\mathrm{K}_{2} \mathrm{O} \\
(\%)\end{array}$ & $\begin{array}{c}\mathrm{Na}_{2} \mathrm{O} \\
(\%)\end{array}$ & $\begin{array}{c}\mathrm{SO}_{3} \\
(\%)\end{array}$ & $\begin{array}{c}\mathrm{L} . O . I^{\mathrm{a}} \\
(\%)\end{array}$ \\
\hline Wack clay & 54.22 & 20.15 & 9.22 & 1.69 & 0.56 & 3.43 & 0.76 & 0.05 & 11 \\
\hline
\end{tabular}

${ }^{\mathrm{a}}$ L.O.I $=$ Loss of Ignition.

The atomic composition as a percentage by mass determined by EDS of the red sawdust is shown in Table 3. Oxygen (46.5 wt\%) and carbon (34.5 wt\%) have the highest content in the red sawdust, this shows that both elements are the elementary constituents of the red wood. Titanium (10.5 wt\%) and silicon (10.0 wt\%) contents are relatively high compared to others and are generally found in these species of trees. They have the advantage of handling high thermal treatment ameliorating the mechanical and chemical resistance of the support. The presence of some elements such as aluminum, magnesium, calcium, potassium and iron with variable grades, which probably originate from substances absorbed by the tree in the soil [27].

Table 3. Chemical composition of the red sawdust by EDS (values are given at $\pm 1 \mathrm{wt} \%$ ).

\begin{tabular}{ccccccccccc}
\hline Composition & $\mathrm{C}$ & $\mathrm{O}$ & $\mathrm{Mg}$ & $\mathrm{Al}$ & $\mathrm{Si}$ & $\mathrm{K}$ & $\mathrm{Ca}$ & $\mathrm{Ti}$ & $\mathrm{Fe}$ & $\mathrm{P}$ \\
\hline $\begin{array}{c}\text { Percentage } \\
\text { content (\%) }\end{array}$ & 34.5 & 46.5 & 0.05 & 0.3 & 10.0 & 0.14 & 0.08 & 10.5 & 0.77 & 0.11 \\
\hline
\end{tabular}

\subsubsection{Thermogravimetric Analysis (TGA) and Differential Scanning Calorimetry (DSC) Analyses}

The temperature evolution of the raw clay sieved at $100 \mu \mathrm{m}$ was characterized by DSC-TGA as shown in Figure 4. The TGA curve is characterized by two main weight losses: from room temperature to $300^{\circ} \mathrm{C}$ for the first one with a loss of $5 \%$ and from $300^{\circ} \mathrm{C}$ to $1200^{\circ} \mathrm{C}$ for the second one, with a total weight loss of $12 \%$. The first loss is attributed to the dehydration of the free physisorbed water present onto the clay whereas the second one may be related to the departure of the water molecules that are embedded inside the two layers of the lamellar structure of the clay, phenomenon known as dehydroxylation. In addition, crystalline water molecules that are part of the clay structure are also eliminated during this last step. This is in agreement with the loss on ignition measured by $\mathrm{XRF}$ up to $1000^{\circ} \mathrm{C}$ that was of $11 \%$ [28] [29]. The temperature evolution of the wack clay sieved at $100 \mu \mathrm{m}$ was characterized by DSC-TGA as shown in Figure 4. 


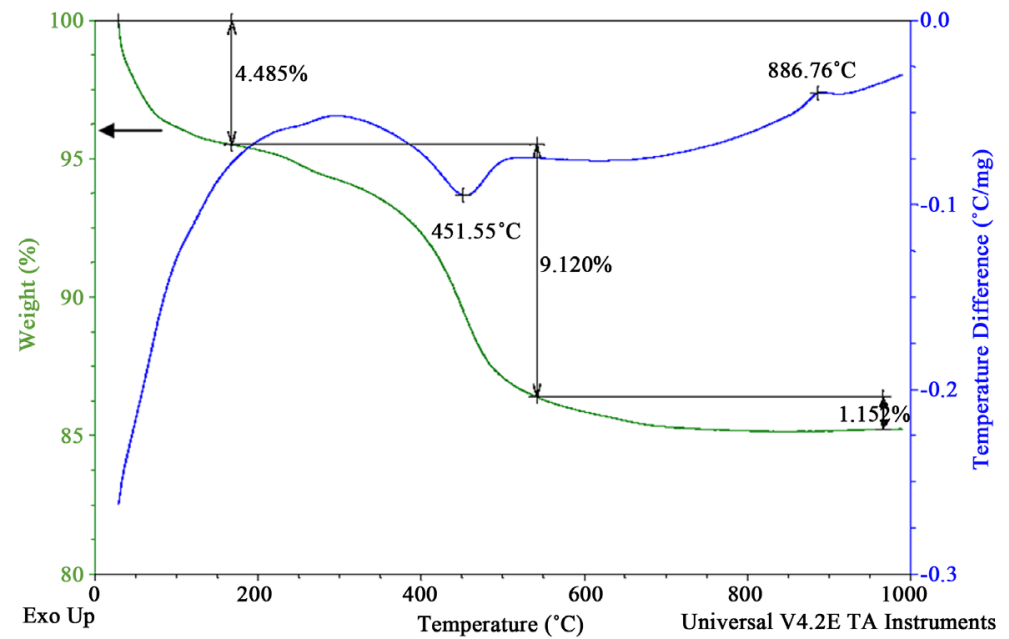

Figure 4. DSC (Blue line)-TGA (green line) curves of the wack clay powder.

The thermal behavior of the sawdust powder was analyzed by DSC-TGA as illustrated in Figure 5. This analysis shows the different weight losses encountered by the sawdust upon firing. From room temperature to $200^{\circ} \mathrm{C}$, we observe the dehydration of sawdust. From $200^{\circ} \mathrm{C}$ up to $500^{\circ} \mathrm{C}$, the organic matter composing the paste is totally degraded, without any residue. This information is decisive in order to determine the temperature-time sintering schedule to be applied to the raw membrane since the sawdust is used as pore-forming agent in its formulation. Since the last exothermic peak on the DSC curve is observed at $427^{\circ} \mathrm{C}$, the heat treatment program was established with a temperature dwelling at $500^{\circ} \mathrm{C}$ for $2 \mathrm{~h}$ to ensure the total elimination of the sawdust [23].

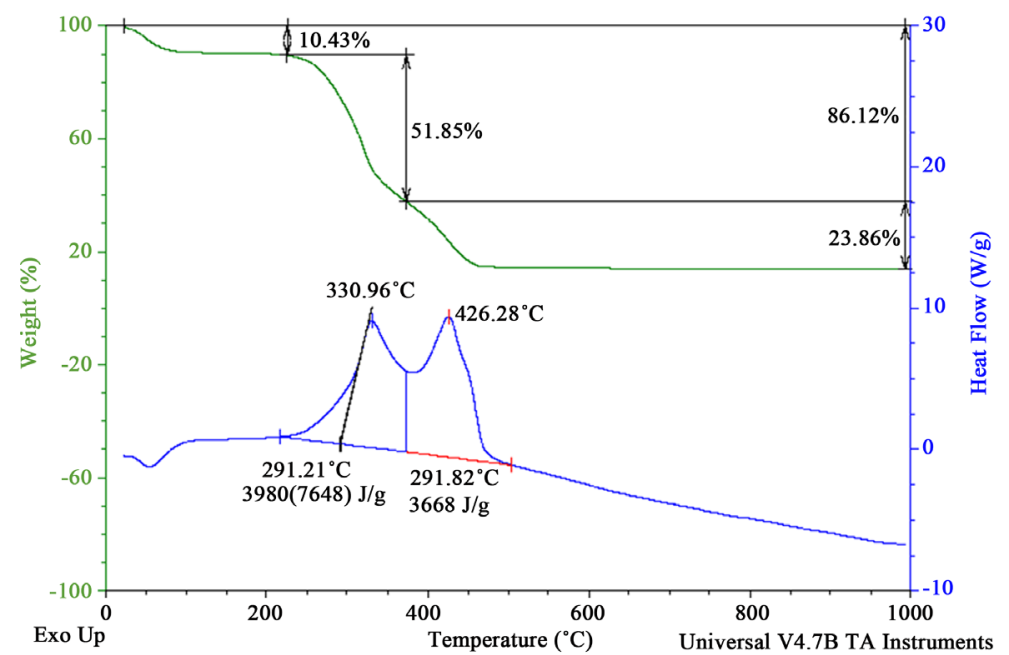

Figure 5. DSC (Blue line)-TGA (green line) curves of the red sawdust powder.

The SEM micrograph of raw sawdust is presented in Figure 6. The fibrous structure of the sawdust is similar to that of wood, with large agglomerates that may be suitable to obtain a porous morphology for the corresponding mem- 
branes. In the sawdust sample the presence of intercellular empty longitudinal cavities as well as the presence of horizontal tubes known as the tracheids which act as support and contact.

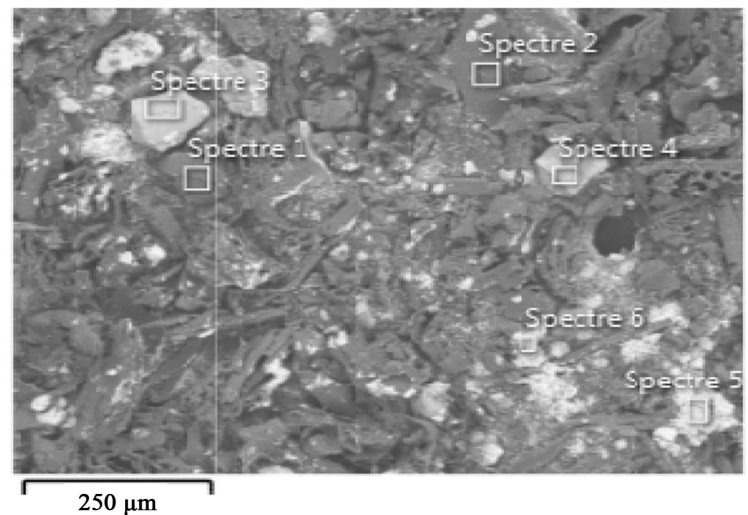

Figure 6. SEM micrograph of the raw sawdust.

\subsection{Optimisation of Ceramic Paste Viscosity}

The experimental plan chosen is a Box-Behnken design with three centre points, each factor requires 3 levels, and the number of experiments is equal to 15 as shown in the experimental design given in Table 4. The residues between the computed values and experimental values, is presented in the table. The residues obtained are very weak and are taken in absolute value. In this table, one notes that the residues obtained are very weak.

Table 4. Experimental design for the viscosity of ceramic paste.

\begin{tabular}{|c|c|c|c|c|c|c|}
\hline \multirow[b]{2}{*}{$\mathrm{N}^{\circ}$} & \multicolumn{3}{|c|}{ Real Values } & \multicolumn{3}{|c|}{ Answer } \\
\hline & $\begin{array}{l}\text { Amount of } \\
\text { porogen }(g)\end{array}$ & $\begin{array}{c}\text { Size of } \\
\text { porogen (\%) }\end{array}$ & $\begin{array}{c}\text { Amount } \\
\text { Binder PVA (g) }\end{array}$ & $\begin{array}{l}\text { Viscosity exp } \\
(\mathrm{Vep})(\mathrm{Pa} \cdot \mathrm{s})\end{array}$ & $\begin{array}{l}\text { Viscosity cal } \\
(\mathrm{Vcal})(\mathrm{Pa} \cdot \mathrm{s})\end{array}$ & $\begin{array}{c}\text { Residue } \\
\text { (Pa·s) }\end{array}$ \\
\hline 1 & 30 & 100 & 3.5 & 25.2 & 24.8 & 0.4 \\
\hline 2 & 20 & 100 & 2 & 18.7 & 19.0 & 0.3 \\
\hline 3 & 30 & 100 & 3.5 & 26.4 & 24.8 & 1.6 \\
\hline 4 & 30 & 100 & 3.5 & 22.8 & 24.8 & 2.0 \\
\hline 5 & 40 & 100 & 5 & 22.7 & 22.3 & 0.4 \\
\hline 6 & 40 & 50 & 3.5 & 12.1 & 12.3 & 0.2 \\
\hline 7 & 30 & 150 & 3.5 & 15.6 & 15.8 & 0.2 \\
\hline 8 & 30 & 50 & 5 & 19.7 & 19.9 & 0.2 \\
\hline 9 & 30 & 150 & 5 & 23.8 & 23.9 & 0.1 \\
\hline 10 & 30 & 50 & 2 & 14.8 & 14.6 & 0.2 \\
\hline 11 & 20 & 150 & 3.5 & 18.6 & 18.3 & 0.3 \\
\hline 12 & 30 & 150 & 2 & 22.6 & 22.4 & 0.2 \\
\hline 13 & 40 & 100 & 5 & 18.2 & 18.3 & 0.1 \\
\hline 14 & 40 & 100 & 2 & 14.8 & 14.7 & 0.1 \\
\hline 15 & 20 & 50 & 3.5 & 10.2 & 9.9 & 0.3 \\
\hline
\end{tabular}




\section{Experimental and Statistical Modeling}

Interpretation starts with the calculation of the coefficients of the model. The coefficients of the model are represented in Table 5 below. The statistical analyses showed that the values of the answers would adapt to a second degree polynomial model. It can be seen that the p-value for the linear factor amount of porogen, the $\mathrm{p}$-value for the quadratic factor amount of porogen-amount of porogen and the $\mathrm{p}$-value for the interaction amount of porogen-size of porogen are close to 1 and consequently their coefficient is close to 0 and thus negligible.

Table 5. Coefficient of the model.

\begin{tabular}{|c|c|c|c|}
\hline Term & coefficient & $\mathrm{T}$ value & P-value \\
\hline Constant & 24.800 & 35.57 & 0.000 \\
\hline \multicolumn{4}{|c|}{ Linear } \\
\hline Amount of porogen & -0.062 & -0.15 & $0.889^{*}$ \\
\hline Size of porogen & 2.975 & 6.97 & 0.001 \\
\hline Amount of binder & 1.687 & 3.95 & 0.011 \\
\hline \multicolumn{4}{|c|}{ Quadratic } \\
\hline Amount of porogen ${ }^{*}$ Amount of porogen & -6.150 & -9.79 & 0.000 \\
\hline Size of porogen ${ }^{*}$ Size of porogen & -4.525 & -7.20 & 0.001 \\
\hline Amount of binder ${ }^{*}$ Amount of binder & -0.020 & -0.08 & $0.940^{*}$ \\
\hline \multicolumn{4}{|c|}{ Interactions } \\
\hline Amount of porogen ${ }^{*}$ Size of porogen & -1.225 & -2.03 & $0.098^{*}$ \\
\hline Amount of porogen ${ }^{*}$ Amount of binder & 2.100 & 3.48 & 0.018 \\
\hline Size of porogen ${ }^{\star}$ Amount of binder & -0.925 & -1.53 & 0.186 \\
\hline
\end{tabular}

*: p-value close to 1 .

Table 6 below gives the criterions of evaluation and validation of the model. The analyses of variance give an $\mathrm{R}^{2}$ value of $97.8 \%$ which is greater than $95 \%$ meaning the model explains $97.8 \%$ the variability of the viscosity of the ceramic paste. The Biais factor is equal to the unit and the AAM (Absolute Average Deviation) equal to the zero thus model is regarded as valid. From the analyses the model obtained was:

Table 6. Criterion of evaluation of the model [28].

\begin{tabular}{ccc}
\hline Validation indicator & Y paste & Reference value \\
\hline $\mathrm{R}^{2}$ & $97.8 \%$ & $>95 \%$ \\
$\mathrm{R}^{2}$ adjusted & $93.8 \%$ & $>90 \%$ \\
$\mathrm{AAD}$ & 0.02 & $0 \leq \mathrm{AAD} \leq 0.2$ \\
Biais & 1.003 & $\leq 1.2$
\end{tabular}




$$
\begin{aligned}
Y_{\text {paste }}= & 24.800-0.062 X_{1}+2.975 X_{2}+1.687 X_{3}-6.150 X_{1}^{2}-4.525 X_{2}^{2} \\
& -0.050 X_{3}^{2}-1.225 X_{1} * X_{2}+2.100 X_{1} * X_{3}-0.925 X_{2} * X_{3}
\end{aligned}
$$

where $X_{1}=$ Amount of porogen, $X_{2}=$ Size of porogen, $X_{3}=$ Amount of binder, $Y$ $=$ Viscosity of ceramic paste.

From the equation of model, the parameters of validation were determined and consigned in Table 6.

\section{- Analysis of variance}

An analysis of the variance, presented in Table 7, made it possible to test the validity of the model. The significance statistical tests (test $\mathrm{F}$ ) showed that the variation due to the regression is significant and that related to the lack of adjustment is non-significant. These results show that the recommended model is valid.

Table 7. Analysis of the variance (ANOVA) results.

\begin{tabular}{ccc}
\hline Source & F value & p-value \\
\hline Model & 24.62 & 0.001 \\
Linear & 21.40 & 0.003 \\
Squares & 46.29 & 0.000 \\
2 factors interaction & 6.19 & 0.039 \\
Inadequation of the adjustment & 0.06 & 0.978 \\
\hline
\end{tabular}

\section{- Contribution of the various factors}

The diagram of contribution informs about the significance of the operational parameters. The negative or positive impact of the variables (amount of porogen, size of porogen and amount of binder) on the output (viscosity of the paste). Figure 7 below shows Pareto Diagram of the viscosity of ceramic paste. From the diagram, we observe that the size of porogen has the highest positive effect on the viscosity of the paste followed by the amount of binder. Meanwhile, the interaction amount of porogen * amount of binder has the only positive effect on the viscosity of the paste. For the quadratic factors, the amount of porogen has the highest negative influence on the viscosity of the paste. Implying that as the amount of porogen is doubled, it influences negatively the viscosity of the paste.

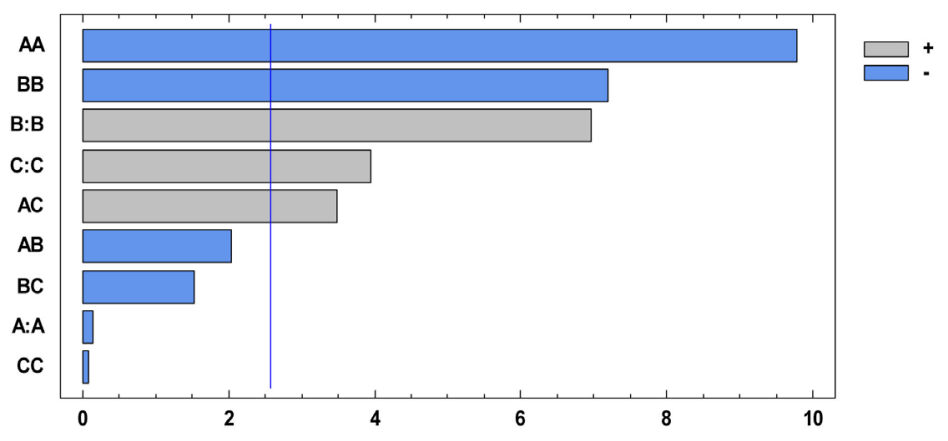

Figure 7. Pareto diagram of the viscosity of ceramic paste. 
Finally, Figures 8-10 present graphical studies in two forms: response surfaces (two dimensional 2D) and iso-response curves (three-dimensional 3D). A major advantage of the design of this experiment is the ability to generate multiple graphic representations of the data. The shaded potion on the iso-response curves represents the optimal zone for the viscosity of the ceramic paste for each interaction.
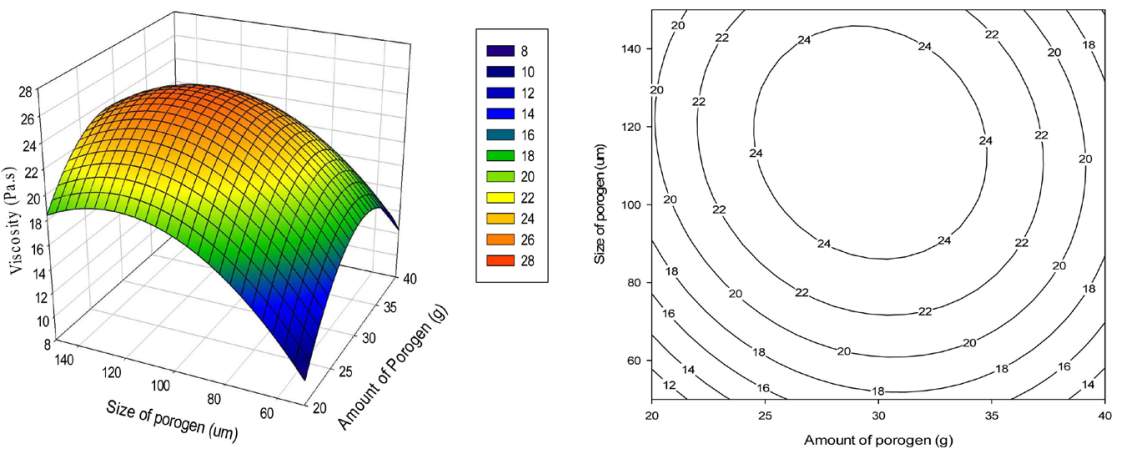

Figure 8. Response surface in $2 \mathrm{D}$ and $3 \mathrm{D}$ (size of porogen * amount of porogen).
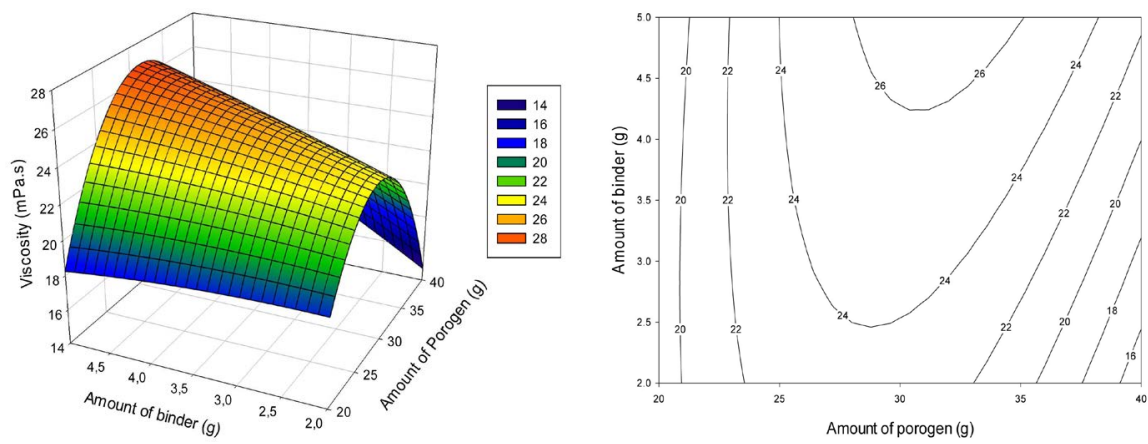

Figure 9. Response surface in 2D and 3D (amount of binder ${ }^{\star}$ amount of porogen).
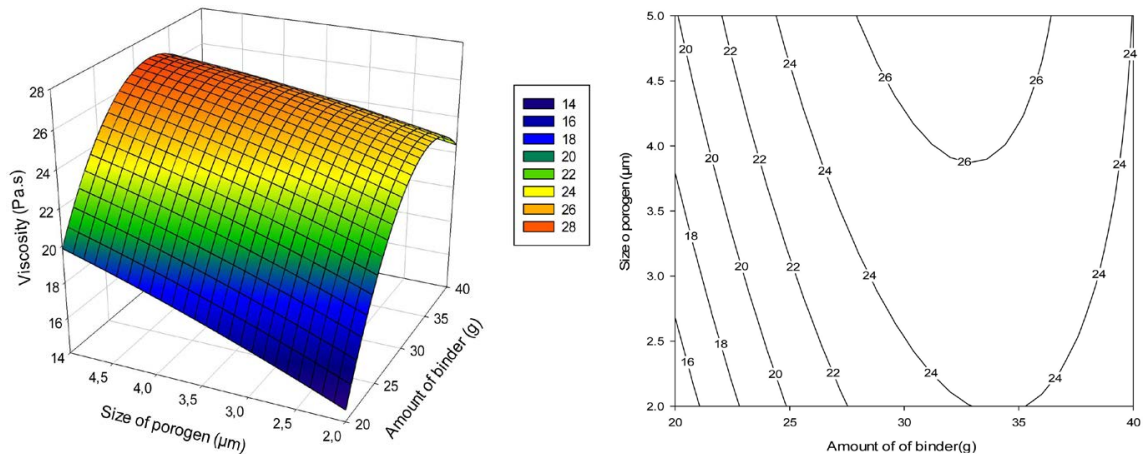

Figure 10. Response surface in 2D and 3D (Size o porogen ${ }^{\star}$ amount of binder).

For the interaction size of porogen ${ }^{\star}$ amount of porogen as shown in Figure 8, for a size of porogen in the range $90 \mu \mathrm{m}$ to $140 \mu \mathrm{m}$ and for an amount of porogen in the range $25 \mathrm{~g}$ to $35 \mathrm{~g}$, we have an optimum (maximum) viscosity of the pate of $24 \mathrm{~Pa} \cdot \mathrm{s}$. Below and above this range of values the viscosity reduces.

For the interaction amount of binder ${ }^{*}$ amount of porogen as shown in Figure 9 , for an amount of binder in the range $4.3 \mathrm{~g}$ to $5 \mathrm{~g}$ and for an amount of poro- 
gen in the range $28 \mathrm{~g}$ to $35 \mathrm{~g}$, we have an optimum (maximum) viscosity of 26 $\mathrm{Pa} \cdot \mathrm{s}$. Below and above this range of values the viscosity reduces.

Table 8 below gives the optimum amount and size of raw material used for the production of the tubular support by the extrusion technique. We have an optimum size of raw material of $100 \mu \mathrm{m}$ for an amount of clay of $66 \mathrm{~g}$, amount of porogen of $30 \mathrm{~g}$ and amount of binder of $4 \mathrm{~g}$. The optimum viscosity of the ceramic paste obtained is $26.7 \mathrm{~Pa} \cdot \mathrm{s}$ which is close to the viscosity of the clay paste of $28.5 \mathrm{~Pa} \cdot \mathrm{s}$, thus good for shaping by the extrusion technique.

Table 8. Optimal amounts and size of raw materials used for the production of tubular support.

\begin{tabular}{cccc}
\hline Factors & Lower level & Higher level & Optimum \\
\hline Size of raw material $(\mu \mathrm{m})$ & 50 & 200 & 100 \\
Amount of porogen $(\mathrm{g})$ & 20 & 40 & 30 \\
Amount of clay $(\mathrm{g})$ & 55 & 78 & 66 \\
Amount binder $(\mathrm{g})$ & 2.0 & 5.0 & 4.0 \\
Viscosity of ceramic paste $(\mathrm{Pa} \cdot \mathrm{s})$ & 24.0 & 28.0 & 26.7 \\
\hline
\end{tabular}

Figure 11 below shows the flow curve for the ceramic paste. It is a graph of viscosity of the ceramic paste against shear rate. We observe on the graph that the more shear rate is applied, the thinner the material becomes. As soon as the shear stress is removed, the viscosity of the fluid will regain its original state. The ceramic paste showed a pseudoplastic behavior.

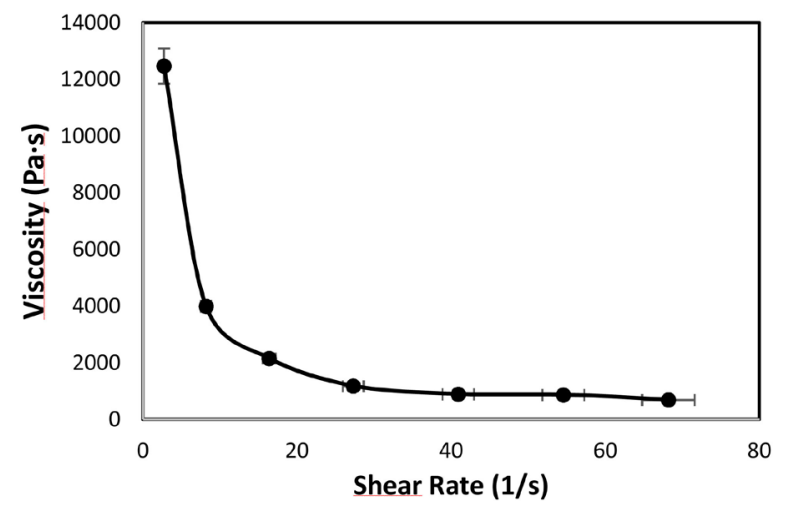

Figure 11. Flow curve for ceramic paste.

\subsection{Characterisation of the Tubular Ceramic Support}

Table 9 summarizes the properties of the prepared tubular ceramic membrane. Figure 12 shows the tubular support before and after sintering. After the sintering of the tubes, certain observations were made on their geometry and their appearance. With regard to the geometry, it was observed that the membranes preserved their geometrical configuration such as outer and inner diameters and length of the tube were $4 \mathrm{~cm}, 2 \mathrm{~cm}$, and $19 \mathrm{~cm}$, respectively. On appearance, the 
heat treatment brought about a change of the color of the tube. This change of colour is due to the presence of Fe (III) in the reaction medium. During sintering, under the influence of the temperature, there is a reaction of oxidation of the iron (II) to iron (III) whose presence in the medium is identified by the reddish colouring, which intensifies according to the content of iron (III). Similar results were obtained by Belibi et al., 2015. It's concluded that the rate of $\mathrm{Fe}_{2} \mathrm{O}_{3}$ in the clay material and the atmosphere of the furnace is responsible for the colouring of ceramics [23].

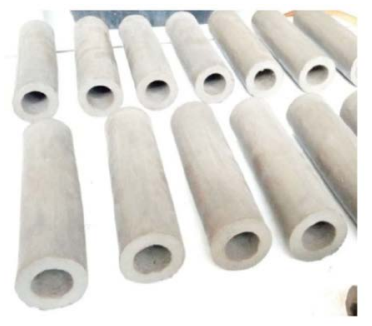

(a)

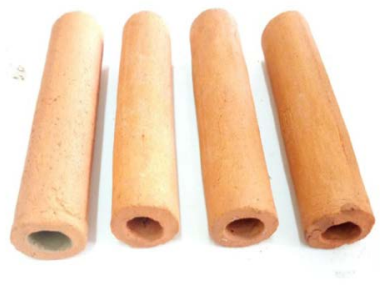

(b)

Figure 12. Tubular ceramic supports, (a) before sintering and (b) after sintering.

Table 9. Properties of the tubular ceramic membrane.

\begin{tabular}{cc}
\hline Properties & Tubular Membrane Support \\
\hline Length $(\mathrm{cm})$ & 19 \\
Outer Diameter $(\mathrm{cm})$ & 4 \\
Channel Diameter $(\mathrm{cm})$ & 2 \\
Unit surface $\left(\mathrm{m}^{2}\right)$ & 0.32 \\
Average pore size $(\mu \mathrm{m})$ & 2.4 \\
Porosity $(\%)$ & 43.5 \\
Water permeability $\left(\mathrm{L} / \mathrm{h} \cdot \mathrm{m}^{2}\right.$ bar $)$ & 244.9 \\
Mechanical strength $(\mathrm{MPa})$ & 9.2 \\
Chemical Stability & \\
Acid-Weight $(\%)$ & 1.9 \\
Base-Weight $(\%)$ & 1.4 \\
\hline
\end{tabular}

The shrinkage in mass of the membrane after drying at $105^{\circ} \mathrm{C}$ was calculated to be $7.63 \%$ and this is due to the departure of interstitial water contained the filters. Meanwhile, after sintering at $950^{\circ} \mathrm{C}$, the shrinkage in mass was calculated to be $31.45 \%$. This reduction is due to the departure of linked water and the water of constitution. This value also corresponds to the loss in mass of the porogen (red sawdust) giving a porous support after sintering.

The open accessible porosity of the fired membrane was found around $43.5 \%$, which is in accordance with values reported in the literature for efficient microfiltration membranes. Porosity is greater than $35 \%$ which is accepted for ceramic filtration [30]. 
The average pore size of the membrane was calculated to be $2.4 \mu \mathrm{m}\left(2.4 \times 10^{-6}\right.$ $\mathrm{m})$. The formulated support is a macroporous membrane adapted for microfiltration. The membrane can be directly utilized for making of multilayer membranes with exclusion of intermediate layers [31].

The average mechanical stability of the membrane was calculated to be 9.2 $\mathrm{MPa}$. This result is in harmony with the results of porosity that showed that the porosity was almost the same for the different samples. In fact, the mechanical strength of ceramic drops when porosity increases [32] [33].

The corrosion resistance test was performed with respect to weight decrement of the membrane after keeping in harsh environments (acid and alkali). The weight decrement of the membrane is calculated to be $1.9 \%$ in acidic condition and $1.4 \%$ in alkali condition. In acid and alkali conditions, the membrane displays an excellent result in resisting corrosion. The loss of weight is $<5 \%$ indicating the support is stable chemically. The obtained results are more commensurable in comparison with the cordierite membrane fabricated by Dong et al. [34].

Figure 13(a) illustrates the water flux of the membrane as a function of time for different applied pressures. A steady flux is been attained with time. The variations of applied pressure on water flux are also presented in Figure 13(b). It can be noticed that the water flux increases linearly with an increase of applied pressures $(0.5$ - 2 bar). This stipulates that the variation in pressure is the barely driving force for permeation. For transportation operation exclusively by convection, the flow rate is proportionate to the pressure, and is in accordance with Darcy's law. The water permeability $\left(L_{h}\right)$ of the membrane was determined by the water flux at different applied pressures. The water permeability $\left(L_{h}\right)$ of the membrane was found to be $244.87 \mathrm{~L} / \mathrm{h} \cdot \mathrm{m}^{2}$ bar.

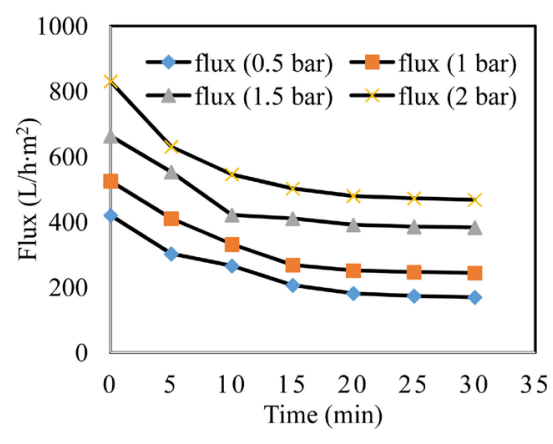

(a)

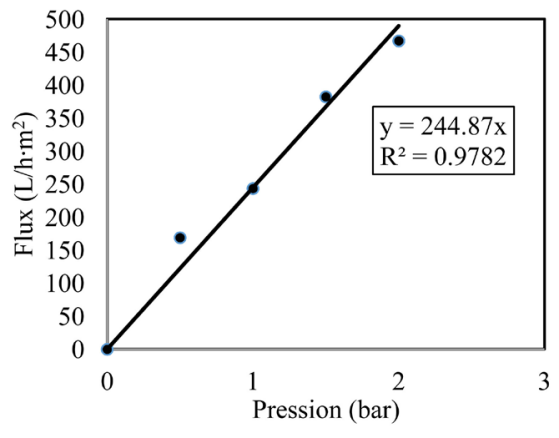

(b)

Figure 13. (a) Water flux as a function of applied pressures and (b) water flux as a function of applied pressure.

\subsection{Filtration Tests}

Applied pressure and feed concentration are the important variables that affect the treatment process in terms of permeate flux and rejection. Hence, the effect of these parameters was investigated as a function of time.

Figure 14(a) shows the permeate flux profiles with time for various applied 
pressures (0.5 - 2 bar) with feed particle size and concentration of $2 \mu \mathrm{m}$ and 100 NTU respectively. It can be seen from the figure that the permeate flux declines sharply at the initial period and becomes gradual there-after in the microfiltration run.

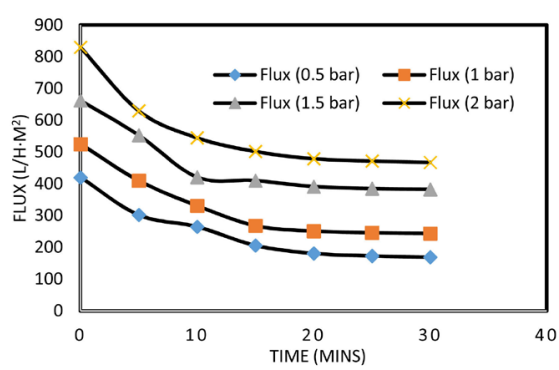

(a)

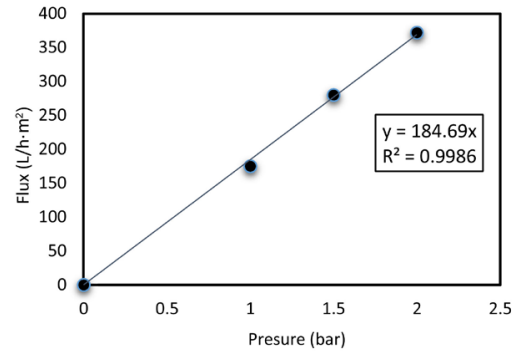

(b)

Figure 14. (a) Water flux as a function of time for five applied pressures and (b) water flux as a function of applied pressure.

The reasons for the flux reductions are owing to concentration polarization on the surface of membrane and blocking of pore in the porous ceramic structure. In addition, it is noticed that the permeate flux increases with increasing applied pressures due to the higher driving forces acted on the membrane. However, the permeate flux profile on increasing applied pressure does not follow the linear trend (Figure 14(b)). This is due to concentration polarization surface that creates further resistances to transport liquid through the membrane [31]. The rate of flux decline is higher at higher applied pressure due to the immediate formation of a clay layer on the surface of the membrane, which makes membrane fouling faster while increasing the applied pressure.

Figure 15 presents the retention of the clay particles with time for various applied pressures. It is noticed that the retention increases with an increase in applied pressure. This occurs due to the fact that higher pressures assist the enrichment of the clay cake formed on the filter leading to pore blockage. The highest retention was obtained at 2 bar with permeability of $184.5 \mathrm{~L} / \mathrm{h} \cdot \mathrm{m}^{2}$ bar with a retention of $96 \%$ for suspensions of 100 NTU decreasing it to 4 NTU. The obtained value of turbidity is conformed to the standards for turbidity value set by the WHO (2012) for potable water which is of 5 NTU [3].

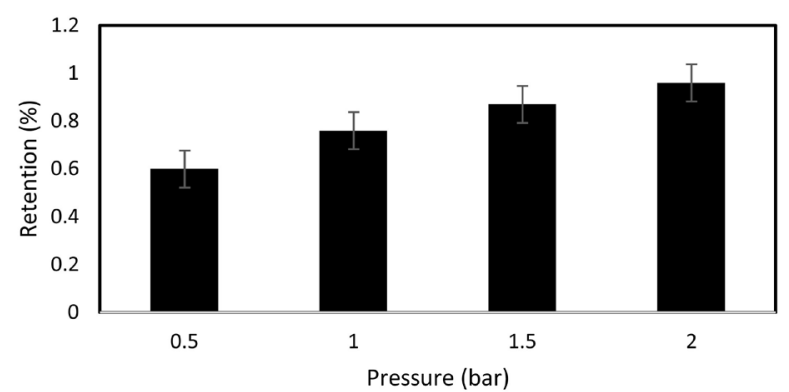

Figure 15. Influence of feed concentration on the retention of suspension for different applied pressures. 


\section{Conclusion}

The aim of this work was to optimize the preparation of ceramic paste used in the production of tubular porous support by extrusion and its application. The optimal size and amount of raw materials obtained are $66 \%$ clay, $30 \%$ red sawdust and $4 \%$ binder for particle size of $100 \mu \mathrm{m}$. The optimal viscosity of the ceramic paste obtained is $26.7 \mathrm{~Pa}$.s which is close to the viscosity of the clay paste only of $28.5 \mathrm{~Pa} \cdot \mathrm{s}$ thus adapted for shaping by extrusion. The prepared tubular membrane support offers a porosity of $43.5 \%$, average pore size $0.24 \mu \mathrm{m}$, a mechanical strength of $9.2 \mathrm{MPa}$ and excellent corrosion resistant making adapted for microfiltration. Microfiltration studies demonstrated that the permeate flux and retention increase with the applied pressure. The membrane support retains until $96 \%$ of suspended particles at 2 bar with permeability of $184.5 \mathrm{~L} / \mathrm{h} \cdot \mathrm{m}^{2}$ bar. The produced tubular support can improve the quality of water in terms of turbidity from 100 NTU to 4 NTU which is below the norms of 5 NTU. In addition, the fabricated tubular membrane is adapted for the coating of a filtration layer which can be applied in ultrafiltration (UF).

\section{Conflicts of Interest}

The authors declare no conflicts of interest regarding the publication of this paper.

\section{References}

[1] Ngatcha, N. (2007) Health and Water Quality Monitoring of Pure Home Water's Ceramic Filter.

[2] Yanu, C. (2016) Application of Pressure Filtration on Ceramic Disc Filters for the Retention of Dissolved and Suspended Particles. Mémoire de Fin d'Études de Master en Chimie Industrielle et Environnement, Université de Ngaoundéré.

[3] WHO (2012) Manganese in Drinking Water. Background Document for Development of WHO Guidelines for Drinking Water Quality.

[4] Cheryan, M. (1998) Ultrafiltration and Microfiltration Handbook. 2nd Edition, CRC Press, Boca Raton. https://doi.org/10.1201/9781482278743

[5] David, O., Gendel, Y. and Wessling, M. (2014) Tubular Macro-Porous Titanium Membranes. Journal of Membrane Science, 461, 139-145. https://doi.org/10.1016/j.memsci.2014.03.010

[6] Fang, J., Qin, G., Wei, W. and Zhao, X. (2011) Preparation and Characterization of Tubular Supported Ceramic Microfiltration Membranes from Fly Ash. Separation and Purification Technology, 80, 585-591. https://doi.org/10.1016/j.seppur.2011.06.014

[7] Burggraaf, A.J. and Cot, L. (1996) Fundamentals of Inorganic Membrane Science and Technology. Elsevier, Amsterdam, The Netherlands. https://doi.org/10.1016/S0927-5193(96)80001-5

[8] Talidi, A., Saffaj, N., Kacemi, K.E., Younssi, S.A., Albizane, A. and Chakir, A. (2011) Processing and Characterization of Tubular Ceramic Support for Microfiltration Membrane Prepared from Pyrophyllite Clay. Scientific Study and Research: Chemistry and Chemical Engineering, 12, 263-268. 
[9] Bouzerara, F., Harabi, A., Achour, S. and Larbot, A. (2006) Porous Ceramic Supports for Membranes Prepared from Kaolin and Doloma Mixtures. Journal of the European Ceramic Society, 26, 1663-1671. https://doi.org/10.1016/j.jeurceramsoc.2005.03.244

[10] Saffaj, N., Persin, M., Younsi, S.A., Albizane, A., Cretin, M. and Larbot, A. (2006) Elaboration and Characterization of Microfiltration and Ultrafiltration Membranes Deposited on Raw Support Prepared from Natural Moroccan Clay: Application to Filtration of Solution Containing Dyes and Salts. Applied Clay Science, 31, 110-119. https://doi.org/10.1016/j.clay.2005.07.002

[11] Masmoudi, M., Larbot, A., Feki, H.E. and Amar, R.B. (2007) Elaboration and Characterization of Apatite Based Mineral Supports for Microfiltration and Ultrafiltration Membranes. Ceramics International, 33, 337-344. https://doi.org/10.1016/j.ceramint.2005.10.001

[12] Hsieh, H.P. (1996) Inorganic Membranes for Separation and Reaction. Elsevier, Amsterdam, The Netherlands.

[13] Mulder, J. (1997) Basic Principle of Membrane Technology. 2nd Edition, Kluwer Academic Publishers, The Netherlands.

[14] Candioti, L.V., De Zan, M.M., Cámara, M.S. and Goicoechea, H.C. (2014) Experimental Design and Multiple Response Optimization. Using the Desirability Function in Analytical Methods Development. Talanta, 124, 123-138. https://doi.org/10.1016/j.talanta.2014.01.034

[15] Khammour, F., Elkouali, M., Kenz, A., Yousfi, S., Talbi, M., Kabbaj, M. and Ainane, T. (2016) A Statistical Approach Based on the Full Factorial Experiment for Optimization of Dyes Adsorption on Biomaterials Prepared from Mint and Tea. Journal of Materials and Environmental Science, 7, 1379-1385.

[16] Sakhale, C.N., Waghmare, S.N., Undirwade, S.K., Sonde, V.M. and Singh, M.P. (2014) Formulation and Comparison of Experimental Based Mathematical Model with Artificial Neural Network Simulation and RSM (Response Surface Methodology) Model for Optimal Performance of Sliver Cutting Operation of Bamboo. Procedia Materials Science, 6, 877-891. https://doi.org/10.1016/j.mspro.2014.07.105

[17] Asfaram, A., Ghaedi, M., Hajati, S., Rezaeinejad, M., Goudarzi, A. and Purkait, M.K. (2015) Rapid Removal of Auramine-O and Methylene Blue by ZnS:Cu Nanoparticles Loaded on Activated Carbon: A Response Surface Methodology Approach. Journal of the Taiwan Institute of Chemical Engineers, 53, 80-91. https://doi.org/10.1016/j.jtice.2015.02.026

[18] Sahoo, B.K., Das, T.K., Gupta, A., De, S., Carsky, M. and Meikap, B.C. (2017) Application of Response Surface Analysis to Iron Ore Slurry Rheology Using Microwave Pre-Treatment. South African Journal of Chemical Engineering, 23, 81-90. https://doi.org/10.1016/j.sajce.2017.03.002

[19] Sadhukhan, B., Mondal, N.K. and Chattoraj, S. (2016) Optimisation Using Central Composite Design (CCD) and the Desirability Function for Sorption of Methylene Blue from Aqueous Solution onto Lemna Major. Karbala International Journal of Modern Science, 2, 145-155. https://doi.org/10.1016/j.kijoms.2016.03.005

[20] Karimizade, A., Takallu, S. and Mirzaei, E. (2018) Evaluating the Effect of pH on Mechanical Strength and Cell Compatibility of Nanostructured Collagen Hydrogel by the Plastic Compression Method. Nanomedicine Journal, 5, 180-185.

[21] Almandoz, M.C., Marchese, J., Pradanos, P., Palacio, L. and Hernandez, A. (2004) Preparation and Characterization of Non-Supported Microfiltration Membranes from Aluminosilicates. Journal of Membrane Science, 241, 95-103. 
https://doi.org/10.1016/j.memsci.2004.03.045

[22] Basumatary, A.K., Kumar, R.V., Ghoshal, A.K. and Pugazhenthi, G. (2015) Synthesis and Characterization of MCM-41-Ceramic Composite Membrane for the Separation of Chromic Acid from Aqueous Solution. Journal of Membrane Science, 475, 521-532. https://doi.org/10.1016/j.memsci.2014.10.055

[23] Belibi Belibi, P., Nguemtchouin, M.M.G., Rivallin, M., Ndi Nsami, J., Sieliechi, J., Cerneaux, S., Ngassoum, M.B. and Cretin, M. (2015) Microfiltration Ceramic Membranes from Local Cameroonian Clay Applicable to Water Treatment. Ceramics International, 41, 2752-2759. https://doi.org/10.1016/j.ceramint.2014.10.090

[24] El Yakoubi, N., Aberkan, M. and Ouadia, M. (2006) Potentialité d'utilisation d'argiles marocaines de Jbel Kharrou dans l'industrie céramique. Comptes Rendus Geoscience, 338, 693-702. https://doi.org/10.1016/j.crte.2006.03.017

[25] Abubakar, I., Birmin Yauri, U.A., Faruq, U.Z., Noma, S.S. and Sharif, N. (2014) Characterization of Dabagi Clay Deposit for Its Ceramics Potential. African Journal of Environmental Science and Technology, 8, 455-459.

https://doi.org/10.5897/AJEST2014.1741

[26] Kamseu, E., Leonelli, C., Boccaccini, D.N., Veronesi, P., Miselli, P., Pellacani, G. and Chinje Melo, U. (2007) Characterisation of Porcelain Compositions Using Two China Clays from Cameroon. Ceramics International, 33, 851-857. https://doi.org/10.1016/j.ceramint.2006.01.025

[27] Salamat, A. (2018) Valorization the Waste of the Wood Industry (Sawdust) and Their Use as Adsorbent Material: Physicochemical Characterization and Modeling of Optimization Sorption Using Statistical Approach. Journal of Materials and Environmental Science, 9, 201-211. https://doi.org/10.26872/jmes.2018.9.1.23

[28] Majhi, A., Monash, P. and Pugazhenthi, G. (2009) Fabrication and Characterization of $\gamma-\mathrm{Al}_{2} \mathrm{O}_{3}$-Clay Composite Ultrafiltration Membrane for the Separation of Electrolytes from Its Aqueous Solution. Journal of Membrane Science, 340, 181-191. https://doi.org/10.1016/j.memsci.2009.05.030

[29] Esharghawi, A., Penot, C. and Nardou, F. (2009) Contribution to Porous Mullite Synthesis from Clays by Adding $\mathrm{Al}$ and $\mathrm{Mg}$ Powders. Journal of the European Ceramic Society, 29, 31-38. https://doi.org/10.1016/j.jeurceramsoc.2008.05.036

[30] Ismaiel, Y. (2012) Micro- and Nano-Porous Adsorptive Materials for Removal of Contaminants from Water at Point-of-Use. PhD Dissertation, Princeton University, Princeton.

[31] Kumar, R.V., Ghoshal, A.K. and Pugazhenthi, G. (2015) Elaboration of Novel Tubular Ceramic Membrane from Inexpensive Raw Materials by Extrusion Method and Its Performance in Microfiltration of Synthetic Oily Wastewater Treatment. Journal of Membrane Science, 490, 92-102. https://doi.org/10.1016/j.memsci.2015.04.066

[32] Hettiarachchi, P., Motha, J.T.S. and Pitawala, H.M.T.G.A. (2010) Identification of an Appropriate Body Composition for Red Clay Products. Cerâmica, 56, 285-290. https://doi.org/10.1590/S0366-69132010000300012

[33] Ali, M.S., Ariff, A.H.M., Jaafar, C.N.A., Tahir, S.M., Mazlan, N., Maori, K.A. and Naser, H. (2017) Factors Affecting the Porosity and Mechanical Properties of Porous Cceramic Composite Materials. In: Hashmi, S., Ed., Reference Module in Materials Science and Materials Engineering, Elsevier, Oxford, 1-54. https://doi.org/10.1016/B978-0-12-803581-8.10131-6

[34] Dong, Y., Feng, X., Dong, D., Wang, S., Yang, J., Gao, J., Liu, X. and Meng, G. 
(2007) Elaboration and Chemical Corrosion Resistance of Tubular Macro-Porous Cordierite Ceramic Membrane Supports. Journal of Membrane Science, 304, 65-75. https://doi.org/10.1016/j.memsci.2007.06.058 